This PDF is a selection from an out-of-print volume from the National Bureau of Economic Research

Volume Title: Essays in the Economics of Crime and Punishment

Volume Author/Editor: Gary S. Becker and William M. Landes, eds.

Volume Publisher: NBER

Volume ISBN: 0-87014-263-1

Volume URL: http://www.nber.org/books/beck74-1

Publication Date: 1974

Chapter Title: The Bail System: An Economic Approach

Chapter Author: William M. Landes

Chapter URL: http://www.nber.org/chapters/c3628

Chapter pages in book: (p. 135 - 163) 


\title{
The Bail System: An Economic Approach
}

\author{
William M. Landes
}

University of Chicago and National Bureau of Economic Research

Widespread dissatisfaction with the current state of criminal justice in the United States has revived interest in the long-standing problem of determining what to do with a person charged with a crime between the time of his arrest and trial.' Should the accused be released or detained during this time interval? What factors are relevant to this decision? What requirements, if any, should be imposed on the accused as a condition of his release? The fundamental issue these questions raise is the difficulty of reconciling the defendant's rights to freedom before his guilt has been formally adjudicated with the community's interest in protecting itself from possible future harm. ${ }^{2}$ In practice, most societies try to

This study has been supported by a grant for the study of law and economics from the National Science Foundation to the National Bureau of Economic Research. I would like to thank Gary Becker, Barry Chiswick, John Hause, Benjamin Klein, and Elisabeth Landes for their criticisms and helpful comments, Elisabeth Parshley for her assistance, and H. Irving Forman for charting the graphs. I also benefited from comments at economic seminars at Columbia University, the University of Chicago, and the University of Massachusetts.

1. See, e.g., John N. Mitchell, Bail Reform and the Constitutionality of Pretrial Detention, 55 Va. L. Rev. 1223 (1969); Laurence H. Tribe, An Ounce of Detention: Preventive Justice in the World of John Mitchell, 56 Va. L. Rev. 371 (1970).

2. The definition of harm is itself an important source of controversy. See, e.g., John N. Mitchell, supra note 1; Laurence H. Tribe, supra note 1. One definition includes only 
resolve this conflict by means of a bail system that establishes rules and procedures to guide decisions on whether or not to release a defendant. These rules may specify which classes of defendants are eligible for release, and require an eligible defendant to make a monetary payment to the court, pledge an asset that will be forfeited if he does not appear for trial, or have a third party assume responsibility for his presence at trial.

In the U.S., the typical procedure is for the court to set a bond as security for the defendant's appearance at trial. If he can post the amount of the bond by pledging acceptable assets or by having a professional bondsman do it for him, he is released; otherwise he is imprisoned. Data presented in Table 1 reveal that a substantial fraction of defendants are in fact imprisoned. A survey of more than 4,000 felony defendants across 70 counties in 1962 showed that 53 per cent of these defendants were confined. A sample of defendants arraigned in New York City in 1971 indicates that 68 per cent of those charged with felonies and 51 per cent of those charged with misdemeanors were imprisoned for average periods of 38 days and 14 days respectively. Moreover, among felony defendants both the likelihood of detention and the average days detained rose the more serious the offense. Table 2 views pretrial detention from a different perspective. It shows that of the more than 127,000 adult inmates in local jails in March 1970 (excluding 25,356 adults not yet arraigned or being held for other authorities), 41 per cent were pretrial detainees. The President's Commission reports that nearly 40 per cent of adults in prison are in local jails. ${ }^{3}$ Thus, about one in 6 adults in prison are persons whose guilt has not been formally determined.

The fact that large numbers of defendants are denied pretrial liberty - whether this is desirable or not-has important implications for the overall operation of the criminal justice system. In the first place, the greater the proportion of defendants not released, the lower the number of trials relative to guilty pleas. The disposition of cases is affected in this way because the costs of going to trial (specifically, the costs of waiting due to court delay) are greater for detained defendants than those re-

the expected losses (e.g., a weakening in the deterrent effect of criminal sanctions) that result when some defendants flee, tamper with evidence, or intimidate witnesses during the period of pretrial release. This leads to the view that the only justification for denying or placing restraints on pretrial liberty is that the defendant's release would seriously impair the proceedings against him. A broader definition of harm also includes predictions about the losses from crimes committed by released defendants. According to this view the potential dangerousness of the defendant is a legitimate reason for denying pretrial liberty.

3. See U.S. President's Comm'n on Law Enforcement \& Admin. of Justice, The Challenge of Crime in a Free Society 172 (1967). 


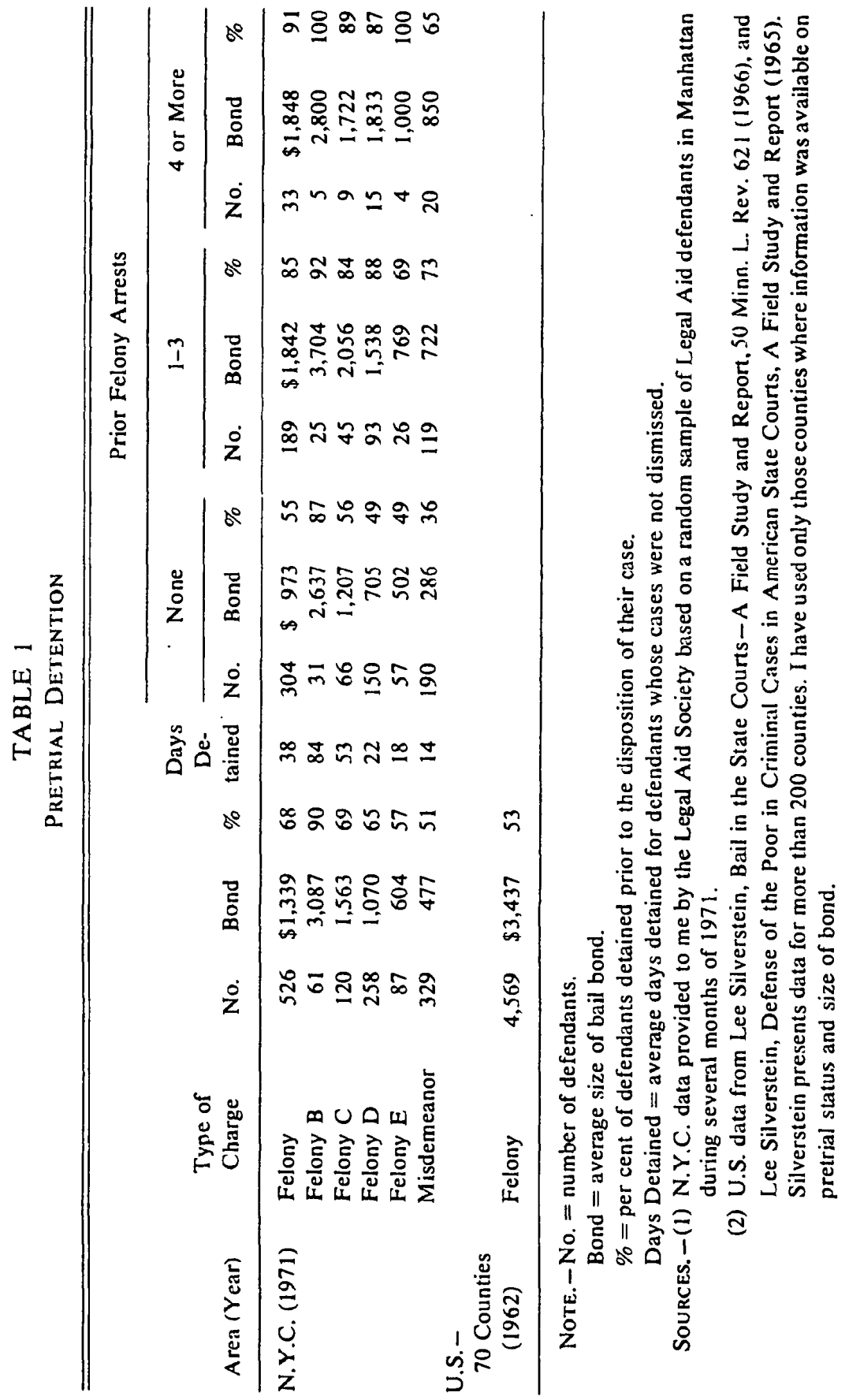


TABLE 2

Defendants Not Released on Ball in Local JaIls, March $1970^{\text {a }}$

\begin{tabular}{ccccc}
\hline \hline & & \multicolumn{2}{c}{$\begin{array}{c}\text { Annual Operating and Capital } \\
\text { Costs Attributed to Inmates } \\
\text { Not Released }\end{array}$} \\
\cline { 3 - 5 } $\begin{array}{c}\text { Inmates Not } \\
\text { Released on } \\
\text { Inmates }\end{array}$ & $\begin{array}{c}\text { Bail and } \\
\text { Awaiting Trial }\end{array}$ & $\begin{array}{c}\text { \% Not } \\
\text { Released }\end{array}$ & $\begin{array}{c}\text { Total } \\
(\$ 000)\end{array}$ & $\begin{array}{c}\text { Per Inmate } \\
(\$)\end{array}$ \\
\hline 127,707 & 52,565 & 41.2 & 161,950 & 3,081 \\
$106,081^{\mathrm{d}}$ & $2,017^{\mathrm{d}}$ \\
\hline
\end{tabular}

Source. - U.S. Dep't of Justice, Law Enforcement Assistance Admin., 1970 National Jail Census 9-11 (Nat'l Crim. Justice Inf. \& Stat. Serv. 1971).

${ }^{a}$ Local jails are those operated locally in municipalities which in 1960 had a population of 1,000 or more. Facilities which normally detain persons for 2 days or less were excluded.

${ }^{b}$ Excludes 25,356 adults who were not yet arraigned or who were being held for other authorities, and 7,800 juveniles.

' Total was $203,967,000$ but this was multiplied by .794 to take account of inmates who were excluded. Operating costs were for 1969 while capital costs were those planned for 1970 .

d Operating costs alone.

leased. Secondly, defendants not released are likely to have higher conviction probabilities in a trial and receive longer sentences if they plead guilty than defendants released on bail. This occurs because detention adversely affects the productivity of the defendant's resources (both market and time inputs). For example, in the case of market inputs detention would hamper consultation with lawyers, and in the case of time inputs detention would make it more difficult to seek out witnesses and engage in other investigatory activities. Finally, if making bail is a positive function of wealth, then the effects of pretrial imprisonment would fall most heavily on low-income defendants. ${ }^{4}$ Recent empirical research on the criminal court system provides some support for these hypotheses. ${ }^{5}$

4. See William M. Landes, An Economic Analysis of the Courts, this volume, for a further development of these arguments.

5. See Willian M. Landes, supra note 4, for an empirical analysis across state county courts using multiple regression techniques. A study by the New York City Legal Aid Society (Brief for Appellee, Bellamy v. Abruczo (N.Y. Sup. Ct., March 1972)) of defendants in New York City also finds a positive relationship between pretrial detention and the likelihood of a prison sentence, holding constant the defendant's prior record, 
The purpose of this essay is to reexamine the important questions of pretrial liberty and bail determination from a different viewpoint than the usual one. Instead of focusing on the desirability of actual bail practices or proposed reforms and their constitutionality, we begin by developing an economic model of an optimal bail system. Our approach is to derive the social benefit from pretrial liberty that incorporates both the gains to defendants from being released on bail and the costs and gains to the rest of the community from their release. We then determine the number of defendants to release and the level of resource expenditures on the bail system that are consistent with the maximization of the social benefit. ${ }^{6}$ After developing the basic model we consider the consistency of the rules derived from an optimal system with some existing practices in the United States: for example, the practice of setting higher bail for more serious offenses and for defendants with prior arrests (see Table 1 for evidence on this), and the rationale of legislation that guarantees a right to bail except for certain classes of defendants (e.g., those accused of capital offenses). Two common views on the proper function of a bail system-deterring flight and preventing future crime-are incorporated into the model as special cases and compared to the more general criterion of maximizing the social benefit.

The main contribution of this essay, however, is the development of alternative methods to select defendants for release. Two basic methods and variations on them are analyzed. Both are consistent with the criterion of maximizing the social benefit function. The first, which corresponds to most existing bail systems, requires defendants to pay for their release. The second compensates defendants for their detention via a monetary or other form of payment. The latter proposal is not only novel but, as we show, is superior in a number of ways to existing bail systems. ${ }^{7}$ The final part of the paper brings into the analysis the advantage of crediting a defendant's pretrial detention against his eventual sentence,

family ties, employment status, and seriousness of the charge. For an early study that supports some of these hypotheses see Anne Rankin, The Effect of Pretrial Detention, 39 N.Y.U.L. Rev. 641 (1964).

6. This model is based on one presented by Gary S. Becker in Crime and Punishment: An Economic Approach, included in this volume. Becker determines the optimal supply of criminal offenses by selecting values for the probability of conviction and the penalty that minimize the community's loss from crime. He does not explicitly consider the bail system, although his approach is applicable to devising rules for an optimal bail system.

7. Gordon Tullock discusses the possibility of compensating defendants not released on bail in The Logic of Law 194-95 (1971). and I have briefly analyzed it. See William M. Landes, pp. $178-79$ this volume. 
the possibility of tort suits by detained defendants who are acquitted, and the role of bail bonds and bondsmen.

\section{THE MODEL}

\section{GAINS FROM RELEASE}

Let us assume that $n$ defendants have been arrested and accused of committing similar types of crimes. From this group some will be detained in jail while others will be released during the period between arrest and trial. Let us also assume that each of the $n$ defendants is expected to do the same amount of harm prior to trial if released on bail. ${ }^{8}$ There are two sources of gains to the community from releasing defendants: the gains to the defendants (whom we assume are members of the community) and the gains to the rest of the community. The gain to the defendant from being released on bail (which is rigorously specified in a later section) depends in part on his earnings outside prison, his wealth, the value he places on the nonpecuniary aspects of pretrial liberty net of the consumption provided him in prison, and any changes in the expected future value of these variables resulting from pretrial liberty (e.g., higher expected future earnings if pretrial release lowers the probability of conviction). ${ }^{9}$ The aggregate gain to all defendants released is the sum of the individual gains and can be written as

$$
G=G(b, t, p, u)
$$

where $b$ is the number released on bail $(b \leqslant n),{ }^{10} t$ is the time from arrest to disposition of a case (or, equivalently, the length of pretrial detention),

8. The assumption of equal harm is not unreasonable in view of the earlier assumption that defendants are accused of similar crimes, which is one indicator of potential harm. We make the assumption of equal harm in order to simplify the presentation of the model. Differences in harm can be handled by dividing $n$ into subgroups of defendants (i.e. $n_{1}, n_{2}, \ldots, n_{n}$ ) where each subgroup consists of persons who are each expected to do the same amount of harm if released on bail. We would then derive the number of defendants to release in each subgroup instead of simply the total number released. The implications of differences in harm are discussed later.

9. All gains and costs in the paper are measured in terms of monetary equivalents.

10. Aggregating the individual gains into the $G$ function depends on which of the $n$ defendants are released. That is, if $b, t, p$ and $u$ were given and defendants differed in their gains from release, $G$ would still be unknown unless one specified which defendants were released. Therefore, we make the following assumption: if only one person is released, it is the defendant witn the highest gain; if two are released, it is the first defendant plus the defendant with the second highest gain, etc. The justification for this ordering will become 
$p$ is the probability of reapprehension for a defendant not appearing at trial, and $u$ is the influence of other factors affecting the gains from release. (Hereafter, residual terms such as $u$ are deleted.) One would expect $G$ to increase as more defendants are released, as the period of release lengthens, and as the probability of recapture falls. That is, $G_{b}>0, G_{t}>$ 0 , and $G_{p}<0$ where $\partial G / \partial b=G_{b}$ (etc.). (The latter notation is used for all derivatives in the paper.)

The second gain from releasing defendants on bail, accruing primarily to members of the community who are not defendants, is the reduction in direct costs of providing detention services, which includes savings on expenditures for jails, guards, food, etc. These savings would increase with $b$ and $t$ as in

$$
J=J(b, t)
$$

where $J_{b}>0$ and $J_{t}>0$. The savings from releasing defendants are not insignificant. The President's Commission estimates that the costs per defendant of pretrial detention are between $\$ 3$ and $\$ 9$ per day. ${ }^{11}$ The data presented in Table 2 indicate that the annual operating and capital costs of pretrial detention facilities are more than $\$ 161$ million, which comes to a cost per defendant of about $\$ 3,000$ annually and $\$ 8.50$ per day.

\section{COSTS OF RELEASE}

It is not costless to release defendants on bail. As previously indicated, harm or damage may result to the community that would not have occurred had these defendants been in custody. The harm will include losses from crimes committed by defendants during the period of pretrial liberty and from a possible reduction in the effectiveness of the legal system as some defendants disappear, tamper with evidence, or intimidate witnesses. ${ }^{12}$ Thus the expected harm from all defendants released on bail can be written:

clearer when methods for releasing defendants are considered. The ordering of $b$ in the functions that are specified later is identical to the ordering in the $G$ function; however, since defendants can be assumed identical with respect to the other functions, the values of these functions are independent of the ordering of $b$.

11. See U.S. President's Comm'n on Law Enforcement \& Admin. of Justice, The Courts 38 (Task Force Report, 1967).

12. As noted earlier (see supra note 2), considerable controversy exists over the desirability of including predictions about future crime in decisions on pretrial liberty. Although we include it, the model would essentially be unchanged by its exclusion. This point is developed later on. 


$$
H=H(b, t, p) \text {. }
$$

$H$ will tend to be greater, the greater the number of defendants released on bail, the longer the period of release and the less likely that defendants are reapprehended. That is, $H_{b}>0, H_{t}>0$, and $H_{p}<0 .{ }^{13}$

A second source of costs (which for convenience are grouped together) consists of expenditures by the state to reapprehend defendants and to affect the length of pretrial release. These costs may be written as

$$
C=C(b, p, t) \text {. }
$$

Since an increase in the probability of reapprehension $(p)$ and a decrease in the period of pretrial release $(t)$ require greater resources, $C_{p}>0$ and $C_{t}<0 . C_{b}$ is assumed positive for two reasons. First, an increase in $b$ is likely to increase the number of released defendants who flee. With $p$ constant, this implies a proportionate increase in reapprehensions and hence greater costs. Second, defendants released on bail are more likely to go to trial (and less likely to plead guilty) than defendants not released, so that an increase in $b$ will increase trial demand. ${ }^{14}$ This in turn will increase court delay and raise $t$ for a given supply of trials. Thus an increase in $b$ with $t$ constant requires greater expenditures on the court system and hence an increase in $C \cdot{ }^{15}$ Note that $C$ is set at 0 when $b=0$

13. Since we assume the expected harm from each released defendant is the same, $H$ can be written as $b \cdot h(t, p)$ where $h(t, p)$ is the expected harm per defendant.

14. See William M. Landes. pp. 176-82 this volume.

15. This point is not as obvious as it may first appear. If one believes that the "quality" of justice resulting from plea bargaining and guilty pleas is about as good as the "quality" from trials, then any additional demand and subsequent expenditures for trial services that result from increasing the number of defendants released is a cost to the community. It is a cost in the following sense: the "quality" of justice is not being enhanced by releasing more defendants but a more expensive method of disposing of cases (i.e., more trials) is being used. Alternatively, if one believed that "quality" is raised by more trials and fewer pleas, then part or all of these additional expenditures on trials should be excluded from the above cost function. These two views come close to those described in "The Crime Control Model" and "The Due Process Model" in Herbert L. Packer, The Limits of the Criminal Sanction 210-21 (1968). For example, "The Crime Control Model" rests on the belief that most persons charged with a crime are "factually guilty" and hence a major cost of making pretrial liberty the norm is that "the increase in time required to litigate cases that don't really need to be litigated would put an intolerable strain on what is already an overburdened process." In contrast, "The Due Process Model" starts from the assumption that the accused "is not a criminal." Pretrial detention and guilty pleas are often undesirable because they lead one "to waive the various safeguards against unjust conviction that the system provides." When large numbers of defendants are detained and plead guilty, "the adversary system as a whole suffers, because its vitality depends on effective challenge." 
because there are no expenditures on $p$, and only the increment in expenditures on the criminal court system that result from a positive $b$ are included in $C$.

\section{Net Benefit Function}

The net benefit from releasing defendants on bail depends on the gain and cost components specified above, which in turn are functions of $b, p$, and $t$. In principle, a number of additional considerations could enter the net benefit function. ${ }^{16} \mathrm{But}$ in the analysis that follows we restrict ourselves to a simple formulation of the net benefit function, which is the sum of the cost and gain components. This measures the monetary equivalent of the net gain from releasing defendants and is denoted by

$$
\pi=G(b, t, p)+J(b, t)-H(b, t, p)-C(b, t, p) .
$$

Optimality requires that we simultaneously select values for $b, t$, and $p$ that maximize the value of $\pi$. By assumption, defendants are selected for release in a way that yields the highest $G$ and therefore the highest $\pi$. Two methods for selecting defendants that satisfy the above assumption are considered. In the first, the defendant pays for his release; in the second, the defendant is paid for remaining in jail prior to trial.

\section{The Defendant Pays}

The $n$ defendants will have a demand function for release on bail that can be written as

$$
b=b(m, t, p)
$$

where $m$ is the price defendants must pay for pretrial release, and $b, t$, and $p$ are defined as before. Since defendants generally differ in the maximum amount they would pay for release, depending on differences in the opportunity cost of their time, wealth, and tastes for nonprison compared to prison life, a decline in $m$ (holding $t$ and $p$ constant) would lead more

16. For example, if one believed that the harm defendants were expected to do was too vague and difficult to predict, $H$ might be given a small weight in the calculation of net benefits. If part of $G$ included the gains to persons from further crimes and this was deemed an inappropriate source of utility, $G$ could be discounted in estimating the net benefit function. Alternatively, if it was strongly felt that defendants later found innocent should not be detained, a greater weight could be given to $G$. (In the extreme, $G$ would be so large that all defendants were released.) 


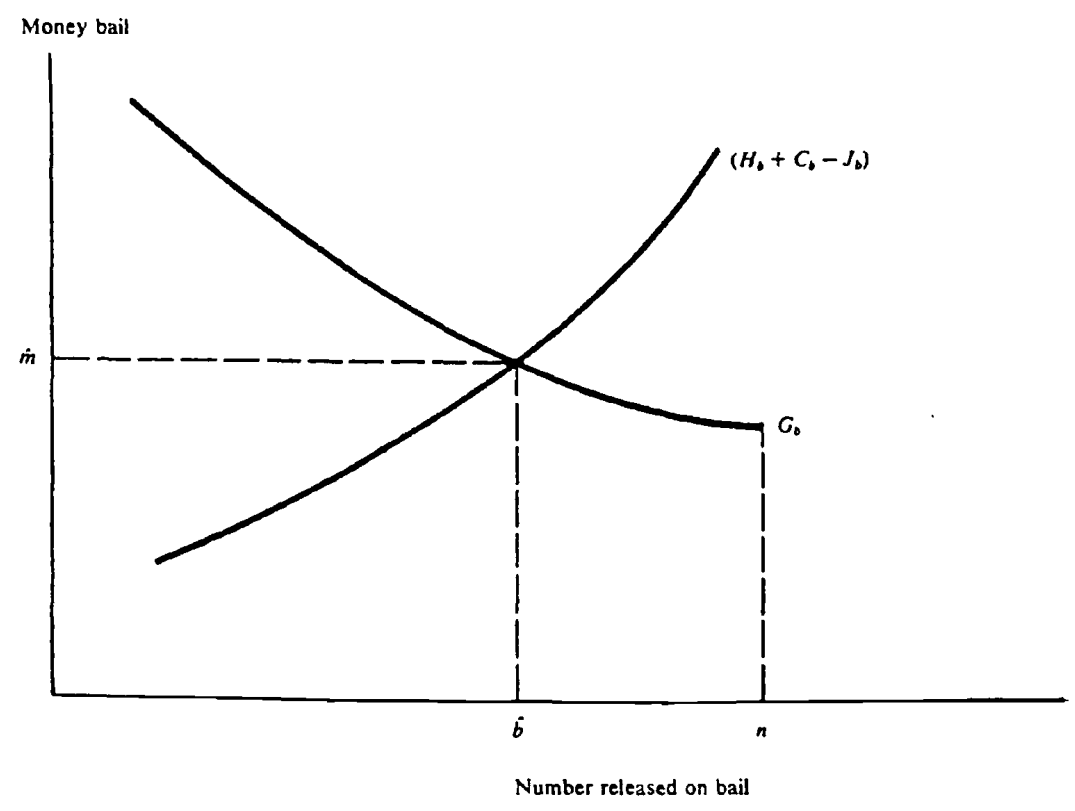

FIGURE 1

defendants to choose release on bail in preference to jail. ${ }^{17}$ Sinilarly, an increase in $t$ and a decrease in $p$ would raise the relative attractiveness of pretrial release and increase its demand. Therefore, we would expect that $b_{m}<0, b_{p}<0$, and $b_{t}>0$.

Now consider the optimality conditions for maximizing the net benefit $\pi$. The variables subject to direct control by the state are $C$, the costs of recapturing defendants and reducing the period of pretrial release, and $m$, the level of money bail or the price of release. These variables determine $b, p$, and $t$ which then determine $\pi$. Maximizing $\pi$ first with respect to $m$ yields

$$
G_{b}=H_{b}+C_{b}-J_{b} \text {. }
$$

In words, money bail should be set at a level where the marginal gain from pretrial release of an additional defendant $\left(G_{b}\right)$ equals the marginal harm

17. Evidence from samples of defendants in the U.S. supports the view that money bail is both negatively related to and an important determinant of the number of defendants released. See, e.g., Note, A Study of the Administration of Bail in New York City, 106 U. Pa. L. Rev. 693 (1958); Charles E. Ares, Anne Rankin \& Herbert Sturz, The Manhattan Bail Project: An Interim Report on the Use of Pre-Trial Parole, 38 N.Y.U.L. Rev. 67 (1967); Note, Compelling Appearance in Court: Administration of Bail in Philadelphia, 102 U. Pa. L. Rev. 1031 (1954); U.S. Atty. Gen'l's Comm. on Poverty \& Admin. of Crim. Justice, Report, app. 1 (1963). 
$\left(H_{b}\right)$ plus marginal costs of reapprehension and expanding court services $\left(C_{b}\right)$ minus the marginal savings in detention costs $\left(J_{b}\right) .{ }^{18}$ Since a defendant would choose release if his gain exceeded $m$, and prefer jail if $m$ exceeded his gain, the optimal number of defendants would be released if $m$ were set at $\hat{m}$ where

$$
\hat{m}=G_{b}=H_{b}+C_{b}-J_{b} .
$$

Thus, defendants are charged a price for release that compensates for the marginal harm and costs minus the savings in detention costs. ${ }^{19}$ The optimum is illustrated in Figure 1 at $\hat{b}$ and $\hat{m}^{20}$

Several implications of the optimality conditions are worth noting.

(1) Wealthier defendants would be willing to pay a higher price for their release on bail because forgone earnings tend to rise with wealth,

18. Although $C$ is the remaining variable subject to control, it is more convenient to maximize $\pi$ with respect to $t$ and $p$. This would determine the optimal level of $C$ given the value of $b$ that satisfies equation (7). In addition to equation (7), the first-order optimality conditions would then include

$$
\begin{gathered}
G_{t}+J_{t}-H_{t}-C_{t}=0 \\
G_{p}-H_{p}-C_{p}=0
\end{gathered}
$$

where (i) and (ii) have been simplified by the substitution of equation (7). We largely ignore (i) and (ii) in the subsequent analysis since our main interest is the determination of $b$ and $m$.

19. At this stage $I$ am ignoring difficulties of financing $m$. These difficulties could lead a person to remain in jail although his gain exceeded $m$ so that the number of defendants released at a price of $\dot{m}$ would be less than optimal.

20. Second-order conditions require that $G_{b b}<H_{b b}+C_{b b}-J_{b b}$ at $\hat{b}$ (where $G_{b b}=$ $\partial^{2} G / \partial b^{2}$, etc.). Figure 1 assumes that $G_{b b}<0$ and $\left(H_{b b}+C_{b b}-J_{b b}\right)>0$. It seems plausible that $G_{b b}<0$ because the ordering of $b$ in the $G$ function is such that additional defendants released value their release by smaller and smaller amounts. $\left(H_{b b}+C_{b b}-J_{b b}\right.$ ) would probably be positive beyond some level of $b$ for two reasons. If the marginal costs of detention rise with the number detained, $J_{b b}$ will be negative (and hence $-J_{b b}>0$ ) since the cost saving will fall as more defendants are released. If there are diseconomies of scale in recapturing defendants and reducing court delay, $C_{b}$ would be a rising function of $b$ and hence $C_{b b}>0$. Note that $H_{b b}=0$ because all defendants are assumed to do the same amount of harm if released. Corner solutions are possible. For example, if $G_{b}>H_{b}+$ $C_{b}-J_{b}$ for all values of $b$, then $b=n$, and if $G_{b}<H_{b}+C_{b}-J_{b}$ for all $b$, then $b=0$.

All defendants are charged the same price for release. In view of our assumptions of similar offenses and equal harm, the use of a single price appears to be consistent with the way bail actually operates. For example, the President's commission reports that "... bail rates are often preordained by stationhouse or judicial schedules: so and so many dollars for such and such a crime. The effect of standard rates and their disparity from place to place is to leave out of consideration not only the important question of a defendant's financial means but also the equally important ones of his background, character, and ties to the community." U.S. President's Comm'n on Law Enforcement \& Admin. of Justice, supra note 3 , at 131 . 
and "days free" are likely to be, in part, a consumption good with a wealth elasticity greater than zero. Other things being equal, this would lead to a greater frequency of pretrial release for defendants with higher incomes, independent of capital market difficulties in financing bail. Although released defendants would be buying their freedom, they would nevertheless be compensating society for the marginal harm and costs of their release via the payment of money bail. ${ }^{21}$

(2) We have assumed that differences among defendants in expected harm do not exist. Suppose these differences exist and are detectable. We could then separate defendants into subgroups where persons in each subgroup were expected to inflict the same harm if released on bail: Subgroups expected to do more marginal harm (i.e., a higher $H_{b}$ with $H_{b b}$ still equal to zero for each subgroup) would generally have money bail set at a higher level and a smaller proportion of defendants released. ${ }^{22}$ In terms of Figure 1, the supply curve would be further to the left for subgroups expected to do more harm, resulting in a higher $m$ and lower $b$ for a given $G$ function.

(3) Suppose there was an exogenous increase in congestion in the court system which increased the delay between arrest and trial. This

21. It has been suggested that bail would be more equitable if it were set with regard to the defendant's ability to pay (i.e., his wealth). In our model this would have the effect of increasing the state's revenue without altering the number or composition of released defendants. Higher prices to wealthier defendants would enable the state to extract some of the defendants' surplus (i.e., consumers' surplus) in Figure 1.

22. The net benefit function can be redefined as follows:

$$
\pi=G\left(b_{1}, b_{2}, \ldots, b_{n}, t, p\right)+J(b, t)-H\left(b_{1}, b_{2}, \ldots, b_{n}, t, p\right)-C(b, t, p),
$$

where $b=b_{1}+b_{2} \ldots+b_{n}$, and where defendants continue to be identical with respect to the $J$ and $C$ functions. Maximizing $\pi$ with respect to the $b_{i}$ 's $(i=1, \ldots, n)$ and setting optimal prices for release yields

$$
\hat{m}_{i}=G_{b_{i}}=H_{b_{i}}-C_{b}+J_{b} .
$$

If we assume that the demand curve for release is the same for the $n$ groups and $\partial\left(H_{b_{i}}\right)$ / $\partial_{b_{i}}=0$. then the greater the group's marginal harm, the lower the proportion released and the higher the price of release. One might argue that a group's demand curve for release would be positively correlated with its marginal harm (i.e., the more harm a defendant is likely to do, the greater is his gain from release on average). Our prediction of a decline in the proportion released as the marginal harm rises would still hold if the $G_{b}$ function shifted up by a smaller amount than the $\left(H_{b}+C_{b}-J_{b}\right)$ function. However, it is by no means obvious that the marginal harm and gain are positively correlated. Innocent defendants are likely to do the least harm if released, and their gain from release may be even greater than for guilty defendants. The former, if detained, incur losses not only in current but also future income resulting from any stigma attached to being in jail. They also may incur sizable search costs to obtain employment after being found innocent and released. 
would raise the defendant's gain from release and shift $G_{b}$ to the right in Figure 1. If increases in $H_{b}$ and $J_{b}$ offset each other as $t$ rises (and $C_{b}$ does not change), there will be no shift in the supply curve and both the optimal $m$ and the number of defendants released on bail will rise. If the change in $H_{b}$ more than offset the change in $J_{b}$, one could no longer predict the direction of change in the number released.

\section{Optimal Bail and Current Practices}

Having set forth the basic model, we now compare some actual bail practices with the prescriptions of an optimal system. ${ }^{23}$ Table 1 shows that the size of the bail bond tends to increase with both the severity of the charge and the number of prior arrests (though this does not hold for every charge and prior arrest class). Not surprisingly, the proportion of defendants released declines with both the severity of the charge and the number of prior arrests. These results are consistent with an optimal system under the assumption that the severity of the charge and prior arrests are indicators of greater marginal harm $\left(H_{b}\right)$ and marginal costs $\left(C_{t}\right)$. The severity of the charge may provide information on marginal harm for two reasons: (1) present charges are one predictor of the damages from possible offenses during the period of pretrial release (holding constant the rate of recidivism); and (2) the more serious the charge, the greater the possible punishment and hence the greater the defendant's gain (the avoidance of punishment being one component) from not appearing for trial. It follows from (2) that the marginal cost of reapprehending defendants $\left(C_{b}\right)$ and the seriousness of the charge are positively correlated since defendants faced with more serious charges have a lower probability of voluntarily appearing for trial. Similar reasoning can be used to relate the number of prior arrests to greater marginal harm and marginal costs. Admittedly, the above arguments are tenuous in the absence of empirical data connecting present charges and prior arrests with marginal harm and marginal costs. Nevertheless, they provide some rationale for present practices in the framework of an optimal system.

23. One difference should be noted at the outset. Money bail, $m$, in the optimal system is a cash payment not returned to the defendant. In actual practice, most defendants are required to post a bond for which they pay a cash fee to a bondsman. However, this difference is not important for the analysis because we can redefine $m$ in the optimal system as the cash fee paid the bondsman. Optimality would then require the state to maximize the net benefit by setting a value for the bond that resulted in the defendant paying the bondsman an amount equal to the payment derived in equation (8). Hence, the use of bonds has little effect on the analysis at this stage and is left for a later section and the appendix. 
For certain offenses, the marginal harm and marginal cost may be so great that it is not feasible for the defendant to compensate the community for his pretrial release. (In terms of Figure 1, the supply curve would be everywhere above the demand curve.) Optimality would be consistent with legislation that prohibited pretrial liberty or permitted the denial of bail for these offenses. In the United States, state and local laws provide defendants with a right to bail in noncapital offenses but permit the denial of bail in capital offenses. Since capital offenses are the most serious, existing laws would appear to conform to the rules of an optimal system. The classic capital offense, murder, does not entirely fit the argument for denying bail to defendants accused of more serious.offenses. Since "most persons who are charged with this offense murder family members or paramours and therefore are the least likely of all offenders to be recidivists," ${ }^{-4}$ the denial of bail could not be based on predictions about committing more murders during the time of pretrial release. Instead, it would have to rest on the contention that persons faced with the prospect of such severe penalties would be most likely to flee. ${ }^{25}$

One can interpret the joint effect of the Eighth Amendment, which states that "excessive bail shall not be required," and legislation that grants a right to bail (except for capital offenses), as requiring that money bail be set according to the amount the defendant can afford without regard to marginal harm and marginal costs. A less extreme position would require setting an upper limit to money bail at a "reasonable" level. If this level were less than the amount that maximized the net benefit function, some defendants would be released even though marginal damages and costs exceeded the gains from their release. In response, one might expect the development of measures that circumvented constitutional and legislative restrictions on setting bail: for example, "preventive detention" in noncapital offenses (in effect, the setting of an infinite bail charge) or the imposition of travel restrictions, requirements of weekly appearances, etc., on released defendants to reduce marginal harm and cost.

\section{Alternative Views of Optimal Bail}

There are two views of bail that dominate much of the current discussion on the topic. The first asserts that the primary function of a bail system is to ensure the defendant's appearance at trial. Money bail should be set, if at all, to prevent flight or more generally to prevent the defendant from

24. See John N. Mitchell, supra note 1, at 1236.

25. This point is made forcefully by Laurence $\mathrm{H}$. Tribe, supra note 1. 
interfering with the proceedings against him. Wherever possible, alternatives to money bail and detention should be encouraged. The second view asserts that the prevention of crimes by defendants during the period of pretrial liberty is a proper concern of the bail process. Accordingly, the potential "dangerousness" of the defendant is a legitimate reason for setting high bail or denying bail altogether. For convenience, the former position is termed the "deterring flight" model and the latter is called the "preventive detention" model. ${ }^{26}$ Both models are special cases of the basic model developed earlier in the paper and, therefore, both can be incorporated into net benefit functions as follows.

$$
\begin{array}{ll}
\text { Deterring Flight: } & \pi_{1}=G_{1}(b, t, p)-H_{1}(b, t, p)-C_{1}(b, p) \\
\text { Preventive Detention: } & \pi_{2}=G_{2}(b, t, p)-H_{2}(b, t, p)-C_{2}(b, t, p) .
\end{array}
$$

There are several important differences between $(5 a)$ and $(5 b)$ at equal values of $b, t$, and $p$. The marginal harm from increasing the number of defendants released $\left(H_{b}\right)$, from lengthening the period of pretrial release $\left(H_{t}\right)$, and from lowering the probability of reapprehension $\left(H_{p}\right)$ are greater in the "preventive detention" than the "deterring flight" model since the former adds another dimension to harm-namely predictions about future crime. Hence, $H_{1 b}<H_{2 b}, H_{11}<H_{2 t}$, and $H_{1 n}>H_{2 p}$. The marginal cost of increasing the number released $\left(C_{b}\right)$ is less in the "deterring flight" model because it does not regard the additional demand for trials that results from releasing more persons as a cost of the bail system. In contrast, a willingness to include the costs of added congestion and greater demand for trials is more characteristic of the "preventive detention" model. Thus, $C_{1 b}<C_{2 l}$. It also follows that the direct costs of reducing the period of pretrial detention or court delay $\left(C_{t}\right)$ would be excluded from the "deterring flight" model. ${ }^{27}$

We can now compare the optimal values of $m, b, t$, and $p$ that are

26. These descriptions are simplifications of the two positions and their many variations. Two recent papers that provide more detailed descriptions are John N. Mitchell, supra note 1, and Laurence H. Tribe, supra note 1. Mitchell argues in favor of the "preventive detention" model, while Tribe argues against it and in favor of the "deterring flight" model. An excellent discussion is also contained in Herbert L. Packer, supra note 15, where "preventive detention" is part of his "Crime Control Model" and "deterring flight" is part of his "Due Process Model."

27. One should note that the savings in detention costs (the $J$ function) have been excluded from (5a) and $(5 b)$ since both models give little or no weight to these savings. We also assume that $G_{1}$ and $G_{2}$ are equal, although it may be argued that the "preventive detention" model tends to overlook these gains. However, the differences already noted in the text between ( $5 a)$ and $(5 b)$ are sufficient for comparing the main implications of the two models. 
obtained from maximizing the net benefit functions in (5a) and (5b). The "deterring flight" model results in a lower money bail and a greater proportion of defendants released than the "preventive detention" model since both the marginal harm and marginal costs (and hence the supply curve in Figure 1) are lower in the former than in the latter. The optimal period of pretrial detention is less in the "deterring flight" model as the marginal cost of reducing this time interval is excluded from the model's specification. This means that court delay or pretrial detention is kept at a minimum (i.e., where $G_{1 t}=H_{1 t}$ ) in the "deterring flight" model. Anything greater lowers the net benefit. Supporters of this model would therefore favor a greater allocation of resources to the judiciary to reduce delay. On the other hand, advocates of the "preventive detention" model would put less emphasis on expanding the court's resources because the resulting marginal benefits (a lower $H$ ) would eventually be offset by the costs of reducing delay. In the latter model, the greater harm that results from longer periods of pretrial liberty is countered by releasing fewer persons. Finally, the optimal probability of reapprehending defendants would be set higher in the "preventive detention" than the "deterring flight" model because one element of harm from a lower probability (i.e., future crime) is explicitly excluded from the latter model.

\section{The Defendant Is Paid}

Let us return to the original model, summarized by the net benefit function in equation (5), with one important change: the defendant is paid to remain in prison instead of paying for his pretrial liberty. He is offered a choice between jail, where he receives $m^{*}$ as compensation, or release on bail, where he receives nothing. To distinguish this system from the one in which the defendant pays, we first consider the effect on the defendant's choice between pretrial liberty and detention.

Figure 2 presents a set of indifference curves between the defendant's wealth and "days free" on bail. We assume that both wealth and "days free" are sources of utility, "days free" are fixed at $t_{0}$, and, provisionally, a defendant forgoes no current or future income if he is jailed. A defendant with an initial wealth of $W_{0}$ would be willing to pay up to $W_{0}-W_{1}$ for his pretrial release. This puts him at $E_{1}$, which is on the same indifference curve as his original position $W_{0}$, and leaves his utility unchanged. Therefore, $W_{0}-W_{1}$ is the monetary equivalent of the defendant's gain from pretrial release when "days free" are the property right of the state. Suppose the state is required to pay the defendant for detaining him. The defendant would now be at $E_{0}$ and not $W_{0}$ since "days free" have become 


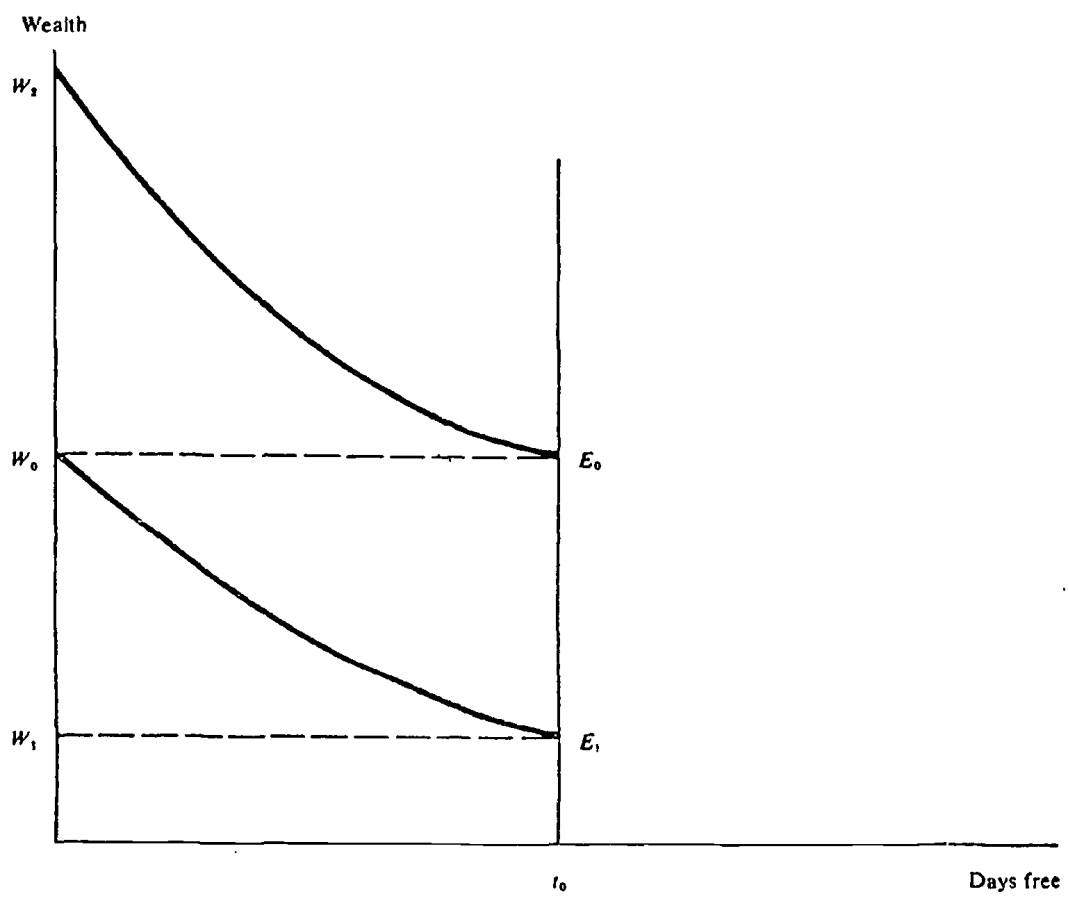

Figure 2

the property right of the individual. This shift in property rights puts the defendant on a higher indifference curve and increases his utility level. The minimum amount he will accept to forgo $t_{0}$ days is $W_{2}-W_{0}$ which leaves him on the same indifference curve as the point $E_{0}$. Thus, $W_{2}-W_{0}$ measures the gain from release when "days free" belong to the defendant. If the slopes of the two indifference curves in Figure 2 are equal at each value of $t$, the indifference curve passing through $E_{0}$ will be everywhere equidistant from the curve passing through $E_{1}$ and $W_{0}-W_{1}$ will equal $W_{2}-W_{0}$. In this instance, "days free" has a zero wealth elasticity so that the amount one will accept to give up his pretrial liberty is identical to the amount one will pay to retain it. The former sum will exceed the latter if "days free" has a positive wealth elasticity (which requires that the absolute value of the slope of the higher indifference curve be greater than the slope of the lower one at each $t) .^{28}$ The analysis remains essentially the

28. With a positive wealth elasticity a further complication arises due to the uncertainty of conviction. To illustrate, suppose the defendant is paid for pretrial detention and there are two states of the world, a conviction state with a probability $P$ and a nonconviction 
same when present or future earnings are lost as a result of pretrial detention. The above monetary gains from release are merely increased by the discounted value of the forgone earnings (i.e., the latter sum is added to both $W_{2}-W_{0}$ and $W_{0}-W_{1}$ ).

The main point of the preceding discussion is that the monetary equivalent of the defendant's gain from release, which is summarized by the $G$ function, and hence the net benefit function depend on the type of bail system specified unless the wealth elasticity of "days free" is zero. To facilitate a comparison among different bail systems, therefore, we will make the simplifying assumption of a zero wealth elasticity and then point out the implications of a positive elasticity. If the defendant were paid to remain in custody, the net benefit function in equation (5) would remain unchanged, and $m^{*}$ would be substituted for $m$ in equation (6). Maximizing $\pi$ with respect to $m^{*}$ would yield equation (7). Since a defendant chooses freedom or jail depending on whether $m^{*}$ is less than or greater than his gain from pretrial release, the optimal number of defendants released would occur when

$$
\hat{m}^{*}=G_{b}=H_{b}+C_{b}-J_{b}=\hat{m} .
$$

Thus, defendants would be paid $\hat{m}^{*}$ to stay in jail and this equals $\hat{m}$, the optimal payment in the system where defendants pay for their release. In terms of Figure 1, all schedules would remain unchanged and, therefore, the number and composition of defendants released would be identical in both systems. If the wealth elasticity of days free were positive, the $G_{b}$ curve would be further to the right in Figure 1 and both $\hat{m}^{*}$ and the number released would be greater than their respective optimal values when defendants must pay for their release.

Although the optimality conditions are the same whether one pays defendants who are detained or defendants pay for their release, there are a number of distinctions to be drawn between the two bail systems.

1. The "presumption of innocence" is part of American legal tradition. Yet, when defendants must pay for their release, persons are jailed without compensation who by definition are not guilty. In effect, "innocent" persons are punished. The conflict between practice and the

state with a probability $(1-P)$. The minimum amount the defendant will accept to forgo his pretrial freedom will be greater in the nonconviction state since he has a higher wealth. We can define the expected amount the defendant is willing to accept as the sum of the amounts in the two states weighted by their respective probabilities. However, the expected amount will differ from the amount he is willing to accept to forgo pretrial release if his tastes for risk are nonneutral. We do not explicitly introduce the latter result into our model since it does not affect the qualitative comparisons between the different bail systems. 
"presumption of innocence" principle has so outraged some persons that they have advocated the virtual elimination of pretrial detention. Others, opposed to this view, cite the potential harm to the community from the release of dangerous persons. However, paying persons for the right to detain them simultaneously satisfies both views. It eliminates the punishment aspect of a bail system since those detained are detained voluntarily and are fully compensated for their losses, and it detains persons where the potential damages to the community exceed the gains from release.

2. A major criticism of requiring defendants to pay for their release is that it discriminates against low-income defendants. ${ }^{29}$ This argument has some support even in the context of the simplified model presented above. Capital market difficulties may make it impossible for certain lowincome defendants to finance their release, although their gain exceeds the money payment required for release. A system of loans from the court to finance release could be instituted, but this brings with it the problem of enforcing repayment. ${ }^{30}$ In contrast, when defendants not released are paid, the charge of discrimination against the poor is eliminated.

3. In a voluntary bail system the community would often pay higher sums to detain defendants the greater the marginal harm and marginal costs of reapprehension that result from their release. In some instances, the payment would be extraordinarily large and possibly infinite. For example, a psychotic defendant accused of multiple premeditated murders and certain to be convicted is likely to value his release highly since it provides him with the opportunity both to escape conviction and to commit additional murders. Although this is an extreme example, it illustrates an obvious problem: a volunteer system provides greater rewards to persons the more dangerous they are or appear to be. The source of the problem is the strict adherence to the principle that "persons are presumed innocent until proven guilty" and, therefore, should not be punished until found guilty. The strict maintenance of a principle can be too costly. If we are willing to compromise, the problem of larger payments to more dangerous defendants becomes tractable. Suppose a particular group of defendants are deemed sufficiently dangerous so that the net benefit function is maximized when all are detained (i.e., the supply curve is everywhere above the $G_{b}$ curve in Figure 1), but the payment to

29. See, for example, U.S. President's Comm'n on Law Enforcement \& Admin. of Justice, supra note 11, at 37-39.

30. The institution of bondsmen for financing bail is relevant here. This is discussed later. 
achieve a zero release rate is unacceptably large. We might simply fix a maximum payment and jail (voluntarily or involuntarily) the entire set of defendants. It must be emphasized that this modification substantially alters the nature of the bail system where defendants are paid. We no longer allow certain defendants the choice between pretrial release or jail. Instead, this decision is made by the court or prosecutor with the stipulation that a jailed defendant receives some compensation.

4. A problem related to the above is that arrested offenders have an incentive to exaggerate their potential harm and desire to escape if released on bail as a means of extracting a higher payment for remaining in jail. Note, however, that this problem exists in reverse when defendants must pay for their release. There, the prosecutor has an incentive to exaggerate the potential danger from releasing the defendant in order to persuade the magistrate to set a higher bail. ${ }^{31}$

5. The physical facilities and living conditions that are provided detained defendants are often deplorable. ${ }^{32}$ This is not surprising because when defendants pay for their release there is little incentive for the state or court to improve these conditions. In contrast, a volunteer or partial volunteer system (i.e., for some offenses the defendant is given the choice between release or jail) would provide such an incentive. Improved detention facilities would reduce the nonmoney costs of detention to defendants, which in turn would reduce the amount the state would have to pay to detain them. The less unpleasant these facilities, the lower the payments. An optimum degree of unpleasantness would be achieved when the marginal costs of improved facilities equaled the marginal savings in payments to jailed defendants.

6. Reducing the time between arrest and disposition has been urged as the best practical solution to problems of the existing bail system. ${ }^{33}$

31. The advantage of high bail to the prosecutor is that it raises the likelihood of convicting the defendant. See William M. Landes, pp. 176-77 this volume.

32. A major complaint of inmates who rioted in the N.Y.C. Tombs (a prison for persons not released on bail) was the overcrowding, inadequate food and presence of roaches, lice, etc. Their complaints were verified by public officials and prison guards. (See New'sweek, August 24, 1970.) Also see U.S. President's Comm'n on Law Enforcement \& Admin. of Justice, supra note 11 , at 38 , on the poor quality of pretrial detention facilities.

33. Chief Judge Harold Greene of the Court of General Sessions in Washington, D.C., has argued as follows:

“. . . A strict policy favoring the detention of criminal suspects is bound to lead to the incarceration of some who will ultimately be acquitted. On the other hand, a liberal release policy has caused and will continue to cause the pretrial freedom of many who will take advantage of their freedom to continue their criminal careers to the detriment of society. Opinions differ as to which is more harmful to our values. ... Whatever one's view on this 
Less pretrial delay would diminish the losses to detained defendants, the harm that released defendants might do, and the direct costs of detention. One could argue that delay would be reduced more when defendants are paid compared to when they pay because the former provides an additional incentive for the state to reduce delay - namely a reduction in the size of payments to attract a given number of volunteers. ${ }^{34}$

7. The two bail systems will have different effects on the deterrence of crime. When defendants are paid, the expected costs of committing crimes are lower than when defendants must pay for their release. In the former, the economic returns to the criminal are higher and, other things remaining the same, the amount of crime will tend to be greater. However, which bail system is preferable on deterrence grounds alone is not obvious. For example, if penalties and probabilities of conviction are optimally set without explicitly considering the bail system, then requiring defendants to pay for their release will impose added penalties that result in overdeterrence. On the other hand, if penalties or probabilities are inadequate, we may move closer to an optimal level of deterrence when defendants pay for their release. Thus, without knowledge of the existing penalties and probabilities, we cannot determine which bail system produces a more desired level of deterrence. Moreover, if penalties and probabilities are adjustable, one can adjust them to achieve the optimal deterrence level for each type of bail system.

\section{SOME MODIFICATIONS}

Two further problems in the development of an optimal bail system are now considered: the "moral hazard" problem, which occurs primarily when defendants are compensated for pretrial detention, and the provision of incentives for defendants released on bail to return for trial. The

issue, no one could reasonably quarrel with the proposition that the most desirable solution to this dilemma is to escape it altogether.

Escape is possible, but only through the construction of a judicial system which tries its suspects so quickly that the incarceration of innocent defendants or the pretrial freedom of potential repeat offenders is so brief as to be acceptable as a practical matter...." (Washington Star, March 30, 1969, at F2, quoted in American Enterprise Institute for Public Policy Research, The Bail Reform Act 47-48 (April 1969).)

34. Note that the optimal amount of delay, $t$, is the same in both bail systems (assuming a zero wealth elasticity of days free) because payments made either by defendants or the state are viewed as transfer payments that do not enter the net benefit function. The inference in the text regarding "additional incentive" is clearly not derived from the optimality conditions but from a view of how the state would actually behave when confronted with a limited budget and having to pay defendants. 
recognition of each problem leads us to devise alternative payment schemes to those previously set forth.

\section{The "Moral Hazard" and Credit Against Sentence}

The "moral hazard" arising when defendants are paid is that a person may commit and confess to a crime, or confess to a crime he did not commit, for the sole purpose of collecting a payment for his detention prior to conviction. This would be most likely to occur for crimes in which the levels of pretrial payments were high relative to the eventual sentence, and for persons with low opportunity costs. One can avoid this difficulty by paying the defendant for pretrial detention only if he is found innocent, and giving him credit toward his sentence for pretrial detention if he is convicted. ${ }^{35}$ With this modification the incentive to confess as a means of receiving pretrial payments would be eliminated since a confession would largely preclude receiving payments. ${ }^{36}$

The payment and credit scheme can be formally incorporated into our model as follows. Both the gains to defendants (the $G$ function) and the savings in jail costs (the $J$ function) from pretrial release will be less than when payments alone are used. The gains from release are less because one must deduct from each defendant's gain the amount he values the credit for pretrial detention. ${ }^{37}$ The savings in jail costs are less when credit is given since we eliminate savings (ignoring discounting) to the community from the pretrial release of defendants who are subsequently

35. In most states pretrial detention is not by law deducted from the sentence received by the convicted defendant. However, some judges make allowance for this when fixing sentence by lowering the latter by the amount of time spent in jail prior to conviction. See Daniel J. Freed \& Patricia M. Wald, Bail in the United States: 1964, at 89-90 (1964).

36. The "moral hazard" problem would not be entirely eliminated because a defendant might initially confess or "plant" evidence making him appear guilty and at the time of trial reveal evidence that resulted in his acquittal. Incentives for such frauds could be reduced by making them subject to penalties. However, it appears unlikely that one could design a bail system that was entirely free of "moral hazards." For example, we previously noted that either the defendant or the prosecutor has an incentive to exaggerate the potential harm from release depending upon which bail system is operative. Moreover, when the defendant pays for his release, the prosecution may purposely impose large costs (including detention) on a person known to be innocent by having a high bail set. Of course, even a system where defendants are paid allows the state to detain innocent persons; however, it raises the cost by shifting the burden of the payment from the accused to the state.

37. Let $g_{i}$ and $g_{i}^{*}$ equal the wealth equivalents of the ith defendant's gain from release when no credit is given and when credit is given, respectively. We want to show that $g_{i}>g_{i}^{*}$. As previously noted (see supra note 28 ), $g_{i}$ is more correctly an expected gain that equals the gain if convicted times $P_{i}$, the probability of conviction, plus the gain if not convicted times $\left(1-P_{i}\right)$. The concept of an expected gain is also applicable to $g_{i}^{*}$. Since 
convicted; their release merely transfers jail costs from the present toward the future. In terms of Figure 1, these factors lead to a downward shift in the demand curve for release (as the gains to defendants fall) and an upward shift in the cost curve (as the deduction for savings in jail costs decline). This in turn results in the release of fewer defendants than when no credit is given. Other things remaining the same, the shifts in these curves will be greater, and hence the decline in defendants released will be greater, the higher the probabilities of conviction, the greater the value defendants attach to credits, and the lower the community's discount rate on savings in future jail costs. In sum, optimal policy will be to detain a greater proportion of defendants when credit is combined with payments than when payments alone are used.

As in the earlier analysis, suppose that varying the size of the payment to defendants is the means by which the state affects the number of defendants released and detained. Here the payment is received only if the defendant is not convicted, since credit is given if he is convicted. At what level should the payment be set to maximize the net benefit function? It can be shown that a uniform payment would not lead in general to the release on bail of the optimal number of persons from our sample of $n$ defendants. ${ }^{38}$ Instead, the state would first determine whether or not the defendant should be detained, and then offer to pay each detained defendant an amount that would induce him to remain in

the gain from pretrial release if convicted is less when credit is given than when it is not by the amount one values the credit (which is equivalent to a reduction in sentence), $g_{i}>g_{i}^{*}$ when $P_{i}>0$. The value of the credit to the defendant will depend on the rate of discount of future "days free," the length of his sentence, and the value of "days free" in the future.

38. Consider two defendants, $A$ and $B$, where their expected gains from pretrial release are respectively

$$
\begin{gathered}
\bar{g}_{a}=\left(1-P_{a}\right) g_{n_{a}}+P_{a} g_{c_{a}} \\
\bar{g}_{b}=\left(1-P_{b}\right) g_{n_{b}}+P_{b} g_{c_{b}},
\end{gathered}
$$

where $P_{a}$ and $P_{b}$ are the probabilities of conviction, $g_{n_{a}}$ and $g_{n_{b}}$ are the gains from release if not convicted, and $\dot{g}_{c_{a}}$ and $g_{c_{b}}$ are the gains if convicted. To simplify, assume that the credit fully compensates for pretrial detention if one is convicted so that $g_{c_{a}}$ and $g_{c_{b}}$ are both zero. Suppose $\bar{g}_{a}<\bar{g}_{0}$ but $g_{n_{a}}>g_{n b}$, and optimality requires that $A$ be detained and B be released (because A's expected gain is less than the net costs of his release while B's expected gain is greater). The minimum contingent payment that $A$ will accept to remain in jail will equal $g_{n_{a}}$, and the minimum that B will accept will equal $g_{n_{b}}$. If a single payment were offered that was sufficient to induce $A$ to remain in jail, then $B$ would also be willing to remain in prison (as $g_{n_{a}}>g_{n_{b}}$ ), contrary to the optimality condition. A uniform payment would be consistent with optimality in the special case where the rank correlation between expected gains and gains if not convicted were equal to 1 (e.g., in the case where the probabilities of conviction were equal for all defendants or where defendants with higher $g_{n}$ 's had lower $P^{\prime}$ s). 
prison. The decision to detain or release would depend on the state's estimate of whether the expected gain to the particular defendant from his release was less or greater than the potential harm from his release plus the costs of reapprehending him and expanding trial services, minus the expected savings in jail costs. Such a policy would be consistent with the maximization of the net benefit function and would lead to the optimal number of defendants released. A more attractive payment scheme might be to defer the setting of payments until the completion of the defendant's case. At that time, if he were found innocent, he could bring a tort action against the state to collect payment both for damages suffered during the period of pretrial detention and for the costs of bringing the action. The sole question before the court would be the amount of compensation since the question of liability would have already been decided by the defendant's acquittal. One who favored a "voluntary" bail system (even if only for certain types of offenses) might initially object to a credit and tort remedy on the ground that it enables the state to detain persons prior to trial without their consent. However, if the tort action permitted the defendant to receive full compensation, the latter would equal what he would have accepted to remain voluntarily in prison prior to the disposition of his case. ${ }^{39}$

\section{INCENTIVES FOR APPEARING AT TRIAL}

In our model, the likelihood of appearing for trial is one of several factors relevant in maximizing the net benefit function. The likelihood of appearing determines in part the harm from releasing defendants and the costs of reapprehending them (since the frequency of attempts to flee will affect the cost of achieving a given probability of reapprehension); however, the net benefit function is also affected by considerations of possible new crimes, the costs of expanding trial services, and the savings in jail costs. Nevertheless, appearing for trial is an important factor and it is worthwhile to consider more explicitly what mechanisms can be devised to provide incentives for the defendant's appearance.

39. When defendants are paid to remain in prison prior to adjudication of their cases but no credit is given, detained defendants will have funds to replace their forgone earnings, enabling them to finance a defense. However, one could argue that with a tort remedy these funds would not be available, which would result in higher probabilities of conviction for those detained compared to those not detained, other things remaining the same. However, this inference is not correct because defendants would be able to make contingent contracts with lawyers who would agree to defend them in exchange for receiving a payment only if their client was acquitted. Similar contracts are common in many tort actions (e.g., negligence cases). 
The most direct method would be to make nonappearance a crime in itself and set appropriate penalties to achieve the optimum deterrence of this crime. ${ }^{40}$ One objection is that the deterrent effect of these penalties is likely to be small because they represent only a marginal increment in the penalty for a defendant likely to be convicted. However, this implies that the appropriate degree of deterrence would require a relatively high penalty for nonappearance and one that is probably in proportion to the penalty for the crime the defendant is initially accused of committing. Moreover, it follows from the optimality conditions of the bail model that defendants accused of the most severe crimes (where penalties for nonappearance may have the smallest deterrent effect) are the least likely to be released on bail.

When defendants must pay for their release, another way to provide an incentive for the defendant's appearance would be to set a money payment or bond that is returned only if the accused appears at trial. In such a system firms are likely to arise that would be willing to accept the risk of nonappearance, and hence forfeiture of the bail bond, in exchange for a fee to compensate them for their expected losses. Thus, an institutional arrangement would come about for shifting the risks of nonappearance from defendants to bondsmen. ${ }^{41}$ In the United States, this is precisely the system that has developed. Of those defendants free on bail, a large proportion were released because a bondsman posted a bail bond. ${ }^{42} \mathrm{~A}$ formal analysis of the bail bond system is presented in the appendix.

It has been alleged that the shifting of potential financial loss to the bondsman removes the incentive for the defendant to appear at trial. This need not be true, for the following reasons: (1) Bondsmen usually require collateral from the defendant. This is a form of sharing or pooling the risks with the accused and thus both suffer losses from nonappearance. (2) The defendant is liable for the amount of the bond should it be forfeited. (3) The bondsmen have an incentive to protect their investment via the expenditure of resources to reduce the likelihood of the defendant's fleeing. This would include periodic checkups of the defendant's whereabouts and threats to revoke the bond (which would make the de-

40. See Gary S. Becker, this volume, for the derivation of optimal penalties for crimes.

41. The analogy to insurance is not perfect, since another important reason for firms specializing in bail bonds is to provide funds for defendants who cannot borrow from banks due, for example, to usury laws or poor collateral.

42. One survey of 19 counties in the U.S. in 1962 indicated that among defendants released, $45 \%$ used professional bondsmen, $35 \%$ had friends or relatives post a bond, $12 \%$ posted cash and $8 \%$ were released on their own recognizance. See Lee Silverstein, Bail in the State Courts - A Field Study and Report, 50 Minn. L. Rev. 621, 647 (1966). I computed these figures by taking averages for the counties where data were given. 
fendant a fugitive). In addition, the bondsman is given the power to arrest a defendant who flees, and there are scattered reports of bondsmen relentlessly pursuing, apprehending, and returning the defendant. ${ }^{43}$ (4) Professional criminals who regularly appear in court have little incentive to flee because bondsmen would be unwilling to post bail for them in the future.

\section{CONCLUDING REMARKS}

The main contribution of this essay has been to propose and analyze an alternative to the existing bail system. This alternative is a system in which the defendant is compensated for his pretrial detention in contrast to the present method of having the defendant pay for his release. Compensation to detained defendants can take a variety of forms that include money payments, credit against sentence for persons subsequently found guilty, and tort remedies for those acquitted. ${ }^{44}$ Our approach was first to derive a net benefit function from releasing defendants prior to trial that incorporated both the gains to defendants and the costs and gains to the community from their release. The optimal number of defendants released was one that maximized the net benefit. Although the optimality conditions were largely unaffected by whether the defendant had to pay or was paid, there are some important advantages to a system in which defendants are compensated. The major one is reducing the punitive aspect of the bail system, since those detained are compensated for losses resulting from their detention. Other advantages include reducing discrimination against low-income defendants and providing incentives for the states to improve pretrial detention facilities.

Criticisms of the existing bail system and proposals for reform play an important role in current policy debates over effective law enforcement. Most proposals call for weakening or even eliminating the requirement that the defendant pay for his release. In its place, these proposals typically advocate extensive investigation of the defendant's background to determine suitability for pretrial release. If he is found suitable, the

43. See Daniel J. Freed \& Patricia M. Wald, supra note 35 , at $30-31$. The incentive to return the defendant to custody, after he does not appear, is that the bondsman is usually given a grace period of about 30 days before he forfeits the bond.

44. The question of whether compensation is a realistic alternative to the existing bail system is beyond the scope of this paper. However, we should note that one difficulty in implementing this proposal is that the majority of voters do not expect to be defendants; therefore, it is unlikely that they would favor a proposal that reduced their wealth and increased the wealth of future defendants. 
defendant may be released without having to post a bond or having only to pay a nominal sum. "Suitability" would be determined on the basis of the defendant's ties to the community, his employment record, past convictions, etc. In New York City some experiments have already been conducted along these lines by the Vera Foundation. The major defect of these proposals is the fate of the defendant not recommended for release. He would be jailed without compensation and thus punished although by law he is still "innocent." In contrast, the proposal advanced in this essay not only lessens the punitive aspect of the bail system by compensating jailed defendants but also provides an incentive to set up investigatory procedures that are advocated in the above proposals. The reason is that paying defendants shifts part of the burden of the bail system from the defendant to the state, and hence there is an incentive for the state to reduce this burden by allocating resources to discovering which defendants are likely to do little harm if released.

\section{APPENDIX}

\section{THE BONDSMAN}

In our model both bail bonds and firms specializing in the sale of these bonds (i.e., bondsmen) were omitted. Let us now introduce them into the analysis, and assume the following: (1) a money payment, denoted by $M$, is set by the court for the defendant's release, but instead of $M$ being paid directly by the defendant, a bondsman posts $M$ with the court in behalf of the defendant; ${ }^{45}$ (2) $M$ will be forfeited only in the event the defendant does not show up for trial (i.e., if the defendant shows up, the bondsman makes no payment to the court); ( 3 ) the bondsman charges the defendant a fee for this service equal to $f \cdot M$ where $0<f<1$ and he may also require some collateral; and (4) competition initially prevails among bondsmen.

Total costs $(T)$ for the group of firms writing bonds will tend to increase with increases in the number of defendants not showing up for trial, the size of $M$, and the time from arrest to disposition. ${ }^{46}$ That is

$$
T=T(p, b, M, t)
$$

45. This system would not prevent the defendant from depositing cash or another asset valued at $M$ to secure release. However, we rule this out in the analysis in order to focus on the bondsman.

46. A longer $t$ implies a greater average volume of bail bonds outstanding at any moment in time. Since we would expect bondsmen to hold reserves (which have an opportunity cost) against the contingency that a defendant will not appear for trial, a longer $t$ will be associated with a greater volume of reserves and hence greater costs. 


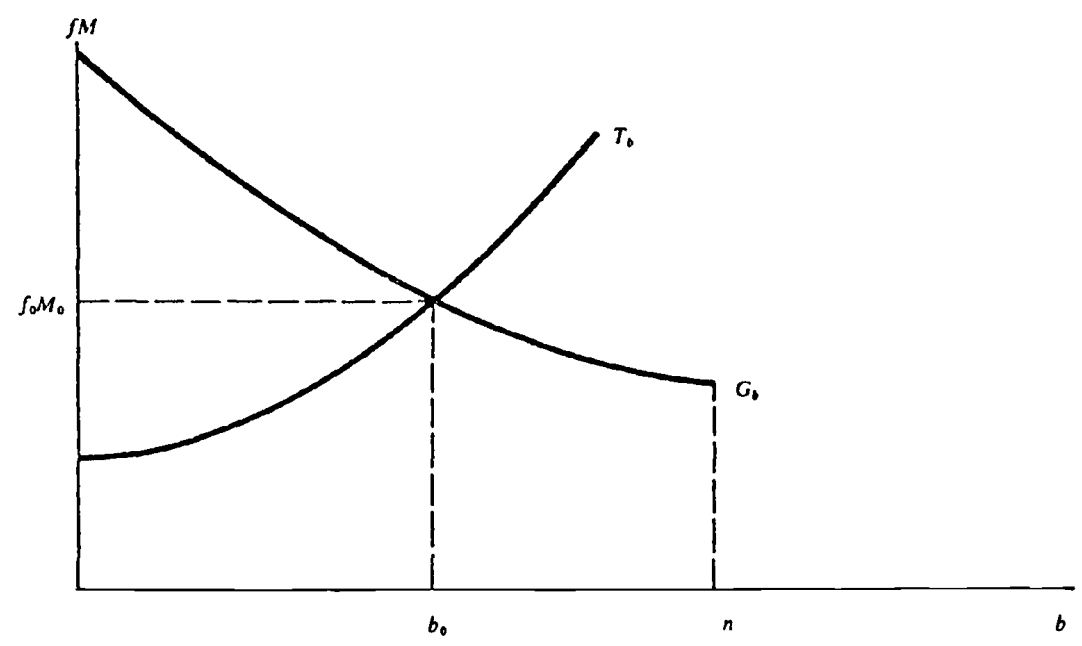

FIGURE 3

where $T_{p}<0, T_{b}>0, T_{M}>0$ and $T_{1}>0$. The demand function of defendants for release on bail is similar to the previous demand function (see equation (6)) and may be written as

$$
b=b(f M, t, p, u)
$$

where $f M$ is the fee to the bondsman, and $t, p$ and $u$ are defined as before except that the residual $"$ would also include the amount of collateral required by the bondsman. Both $b_{f}(=\partial b / \partial f M \cdot(M))$ and $b_{M}$ are assumed to be negative. If $M$ were set at $M_{o}$ (and $t$ and $p$ are given), equilibrium in the market for bail bonds would take place at $f_{0} M_{0}$ and $b_{0}$ in Figure 3. At higher levels of $M$, for example, $T_{b}$ shifts to the left, $f M$ rises and $b$ falls. Thus, to maximize the net benefit function $\pi$ (see equation (5)), $M$ would be set by the court at a value where the number of defendants released on bail in Figure 3 was equal to the number that maximized $\pi .^{47}$ That is

$$
f M=T_{b}=G_{b}=H_{b}+C_{b}-J_{b} .
$$

Although the optimal $M$ in (12) would be greater than the optimal money payment $(\dot{m})$ in the model that excluded the bondsman, the number of defendants released on bail and the actual payment for release would be the same.

Let us drop the assumption of a competitive market in the sale of bail bonds, and instead assume a cartel agreement among bondsmen where entry is restricted and the fee for bonds is set above the competitive price. Both fee-fixing and entry

47. We do not explicitly consider the resource costs of bondsmen in the net benefit function. 
restrictions are enforced by the state ${ }^{48}$ The cartel would take a curve marginal to the demand curve in Figure 3 (assuming no price discrimination) and for a given $M$ this would result in a higher $f M$ (i.e., a higher $f$ ) and fewer defendants released than in the competitive case. ${ }^{49}$ However, the state could compensate for the cartel by lowering $M$ below the competitive level in order to release on bail the optimal number of defendants.

48. Some form of state regulation appears to be the rule. For example, in large metropolitan areas bonds are generally written by agents (bondsmen) of surety companies that are regulated as part of the insurance business. Fees and minimum cash reserves are set by the state. Bondsmen are also licensed in some states. In addition, there exist laws prohibiting bondsmen from giving rebates to attorneys and public officials in exchange for recommending clients, and from soliciting business in courtrooms. See Daniel J. Freed \& Patricia M. Wald, supra note 38 , at 36-38.

49. This would require

$$
\begin{gathered}
f M=G_{b}=H_{b}+C_{b}-J_{b} \\
f M\left(1+\frac{1}{e}\right)=T_{b},
\end{gathered}
$$

where $e$ is the elasticity of the demand curve $G_{0}$ in Figure 3. With the same number of defendants released in the competitive and monopoly cases, the fees to defendants $(f M)$ are also the same. However, $f$ is larger and $M$ smaller with monopoly than competition. 